\title{
Flexible magnifying endoscopy with narrow band imaging for the diagnosis of uterine cervical tumors: A cooperative study among gastrointestinal endoscopists and gynecologists to explore a novel microvascular classification system
}

\author{
NORIKO NISHIYAMA ${ }^{1}$, KENJI KANENISHI ${ }^{2}$, HIROHITO MORI $^{1}$, HIDEKI KOBARA $^{1}$, SHINTARO FUJIHARA ${ }^{1}$, \\ TAIGA CHIYO $^{1}$, NOBUYA KOBAYASHI ${ }^{1}$, TAE MATSUNAGA ${ }^{1}$, MAKI AYAKI ${ }^{1}$, TATSUO YACHIDA ${ }^{1}$, \\ AYAKO FUJIMORI $^{1}$, MAKOTO ORYU ${ }^{1}$, CHIAKI TENKUMO ${ }^{2}$, MEGUMI ISHIBASHI ${ }^{2}$, UIKO HANAOKA ${ }^{2}$, \\ TOSHIYUKI HATA $^{2}$, YUMI MIYAI ${ }^{3}$, KYUICHI KADOTA ${ }^{3}$, REIJI HABA ${ }^{3}$ and TSUTOMU MASAKI ${ }^{1}$
}

Departments of ${ }^{1}$ Gastroenterology, ${ }^{2}$ Gynecology and ${ }^{3}$ Diagnostic Pathology,

Faculty of Medicine, Kagawa University, Miki, Kita, Kagawa 761-0793, Japan

Received October 28, 2015; Accepted February 17, 2017

DOI: $10.3892 / \mathrm{ol} .2017 .6157$

\begin{abstract}
Narrow band imaging with magnifying endoscopy (NBI-ME), which is useful for the assessment of micro-vessels, has excellent diagnostic potential for early gastrointestinal epithelial neoplasia. Conventional diagnostic tools for uterine cervical epithelial tumors are still unsatisfactory. An accurate diagnostic tool for uterine cervical epithelial tumors is required to preserve the reproductive ability of young women with uterine cervical tumors. Flexible NBI-ME was performed in patients with cervical squamous cell lesions that required further examinations based on their Pap smear results (cytology $\geq$ low-grade squamous intraepithelial lesion) at Kagawa University Hospital between April 2014 and April 2015. NBI-ME results concordant with the punch biopsy sites were compared with the histological results. A retrospective review of the NBI-ME images identified abnormal NBI-ME results regarding micro-vascular patterns. All images were categorized as having abnormal features. NBI-ME revealed the following vascular pattern differences of different stage tumors: Dot-like vessels without irregular arrangements and high density in cervical intraepithelial
\end{abstract}

Correspondence to: Dr Hideki Kobara, Department of Gastroenterology, Faculty of Medicine, Kagawa University, 1750-1 Ikenobe, Miki, Kita, Kagawa 761-0793, Japan

E-mail: kobara@med.kagawa-u.ac.jp

Abbreviations: NBI-ME, narrow band imaging with magnification endoscopy; GI, gastrointestinal; CIN, cervical intraepithelial neoplasia; CIS, carcinoma in situ; MIC, microinvasive cancer; IC, invasive cancer; ESD, endoscopic submucosal dissection

Key words: flexible magnifying endoscopy, narrow band imaging, uterine cervical tumors, microvascular classification, cooperative study neoplasia (CIN) CIN1-CIN2; dot-like vessels with irregular arrangements and high density in CIN3-carcinoma in situ; crawling vessels in minimum invasive cancer; and willow branch vessels and new tumor vessels in invasive cancer. NBI-ME may be an effective diagnostic tool for uterine cervical epithelial tumors, which may lead to the establishment of a novel classification system.

\section{Introduction}

At present, uterine cervical cancer is a common malignant neoplasm in females (1), and $40 \%$ of cervical cancer patients are diagnosed during reproductive age. Therefore, invasive surgeries to remove cervical cancer should be avoided in suitable cases to preserve childbearing abilities (2).

While the Pap smear is the standard cervical cancer screening method, the overall sensitivity (65\%) of the Pap smear is not satisfactory (3). Abnormal results from a Pap-screening test are followed by a colposcopy for histological confirmation. However, colposcopy also fails to detect $30-50 \%$ of prevalent high-grade squamous intraepithelial lesions (4). While the current colposcopic classification system intends to improve the performance of colposcopy, accurate diagnostic yield is still $<55 \%$, even for cervical cancer (5).

Narrow band imaging with magnifying endoscopy (NBI-ME), which is useful for the assessment of micro-vessels, has demonstrated outstanding ability for the detection of early gastrointestinal (GI) epithelial neoplasia (6-12). Magnifying endoscopy enables the capture of images $\leq 80$-fold compared with conventional endoscopy. The NBI system is an advanced optical system, which enhances the visualization of micro-vascular architecture and micro-surface structures using narrower bands of blue and green filters compared with conventional white light imaging (13). Therefore, ME-NBI, a combination of magnification endoscopy and NBI, may improve the detection and diagnosis of GI neoplasia with specific micro-vascular and surface abnormalities. The 
associations between ME-NBI appearance and pathology of non-neoplastic and neoplastic lesions have been demonstrated with strong clinical evidence. A number of diagnostic classification systems for GI neoplasia have been established by clarifying these characteristic ME-NBI findings $(6,7,12)$. Notably, the ME-NBI findings of irregular micro-vascular pattern with a demarcation line and/or irregular micro-surface pattern with a demarcation line have been proposed to be essential for accurate diagnosis of early gastric cancer (7). Therefore, ME-NBI may have important roles in the diagnosis of distinguishing between GI cancerous and noncancerous lesions.

Therefore, the ability of NBI-ME to diagnose uterine cervical lesions was determined by performing a collaborative study with GI endoscopists and gynecologists.

\section{Patients and methods}

Patients and methods. Flexible NBI-ME was performed in patients with squamous cell cervical lesions that required further examinations based on their Pap smear results (cytology $\geq$ low-grade squamous intraepithelial lesion) at Kagawa University Hospital (Miki, Japan). Patients with cervical adenocarcinoma were excluded. A total of 10 patients with a mean age of 39 years (range, 29-65 years) who underwent NBI-ME between April 2014 and April 2015 were enrolled in the present study. A magnifying endoscope (GIF-H260Z; Olympus Corporation, Tokyo, Japan) with an NBI system (EVIS EXERA II; Olympus Corporation) was used during all procedures. Two experienced endoscopists performed endoscopic examinations of the cervix with one senior gynecologist. The present study was approved by the Ethics Committee of Kagawa University Hospital and was registered under the UMIN no. 000014933. Written informed consent was obtained from all patients.

Endoscopic procedure. Transvaginal endoscopic examination was performed by an endoscopist at the endoscopy unit (Kagawa University Hospital) and a gynecologist, who assisted using a Cusco speculum to obtain cervical visibility. The entire circumference of the cervix was observed under white light imaging, and NBI-ME was continuously utilized. The observation procedure was performed at long, middle, and short distances (max 80 power zoom; similar to endoscopic examination of the GI tract). The NBI-ME findings were recorded to develop a schema of the cervix (Fig. 1A). A normal uterine cervix was characterized by an internal ostium of the uterus with columnar, transitional and squamous epithelium in order from the inside. Intrapapillary protruded loop vessels, which appeared in the area of transitional and squamous epithelium were defined as dot vessels. A representative normal uterine cervix is presented in Fig. 1B-D.

A gynecologist then performed a routine colposcopy and obtained punch biopsies at the abnormal site (according to the NBI-ME examinations). An abnormal appearance during a colposcopy is defined as mucosal thickness with whitish or abnormal vessels (mosaic or punctuated patterns). Histological results were confirmed with punch biopsies obtained during colposcopy or conization and extended hysterectomies. Biopsy tissues were fixed in $10 \%$ neutral-buffered formalin and were further processed into paraffin-embedded blocks. Sections (3 $\mu \mathrm{m})$ were cut from each paraffin block. Pathology was assessed by three experienced pathologists using a light microscope (Eclipse 55i; Nikon Corporation, Tokyo, Japan) based on hematoxylin and eosin staining.

Outcome measures. NBI-ME findings concordant with the punch biopsy sites were compared with the histological results. A retrospective review of the NBI-ME images identified the following abnormal NBI-ME findings regarding micro-vascular patterns: i) presence of dot vessels, where a dot was defined as a dilatation of an intrapapillary protruded loop vessel; ii) irregular arrangement of dots; iii) high density of dots; iv) caliber change of the micro-vasculature; and v) new tumor vessels, defined as a dilated vessel two times larger than the perivascular vessels. All images were categorized as having abnormal features by the consensus of two experienced endoscopists.

\section{Results}

A total of 10 patients underwent endoscopic examinations using NBI-ME for the detection of cervical abnormalities. The final diagnoses (based on histology) were as follows: Negative for intraepithelial lesion or malignancy (NILM; $n=1$ ), CIN1 $(n=2)$, CIN2 $(n=2)$, CIN3 $(n=1)$, CIS $(n=2)$, microinvasive cancer (MIC; $n=1)$, and invasive cancer (IC; $n=1$; Table I). The detection rate of abnormal cervical lesions was $90 \%(9 / 10)$, excluding one normal case.

Microvascular features of the uterine cervix were evaluated by NBI-ME. The vascular patterns of the cervical tumors at each stage were different. Dot like vessels were observed in 7 patients with cervical disease: CIN1 $(n=2)$, CIN2 $(n=2)$, CIN3 $(n=1)$, and CIS $(n=2)$. Irregular arrangements were observed in 5 patients: CIN3 $(n=1)$, CIS $(n=2)$, MIC $(n=1)$, and IC $(n=1)$. Tumor stage was similar in patients with high density dots compared with patients with irregular arrangements. Caliber changes were observed in 2 cases: MIC $(n=1)$ and IC $(n=1)$. New tumor vessels were observed in one case: IC $(n=1)$. No adverse events resulted from the NBI-ME observations. The NBI-ME findings from patients with CIN1, CIN2, CIN3, CIS, MIC, and IC are summarized in Table II. CIN1 was defined as a slight increase in the number of dots compared with normal tissues (Fig. 2). CIN2 was defined as a mild increase in the number of dots compared with normal tissues (Fig. 3). CIN3 was defined as the elongation of dots with slightly irregular arrangements and a large increase in the number of dots compared with normal tissues (Fig. 4). CIS was defined as the elongation of dots with severely irregular arrangements and a large increase in the number of dots compared with normal tissues (Fig. 5). MIC was defined as the presence of crawling vessels with irregular arrangements, high densities and caliber changes (Fig. 6). IC was defined as the presence of irregular, high density willow branch vessels and new tumor vessels (Fig. 7). Histological findings of the different stages were demonstrated in Figs. 2-7, respectively (hematoxylin and eosin staining; magnification, x20). A novel classification system (Table III) was proposed based on the data from the present study. 


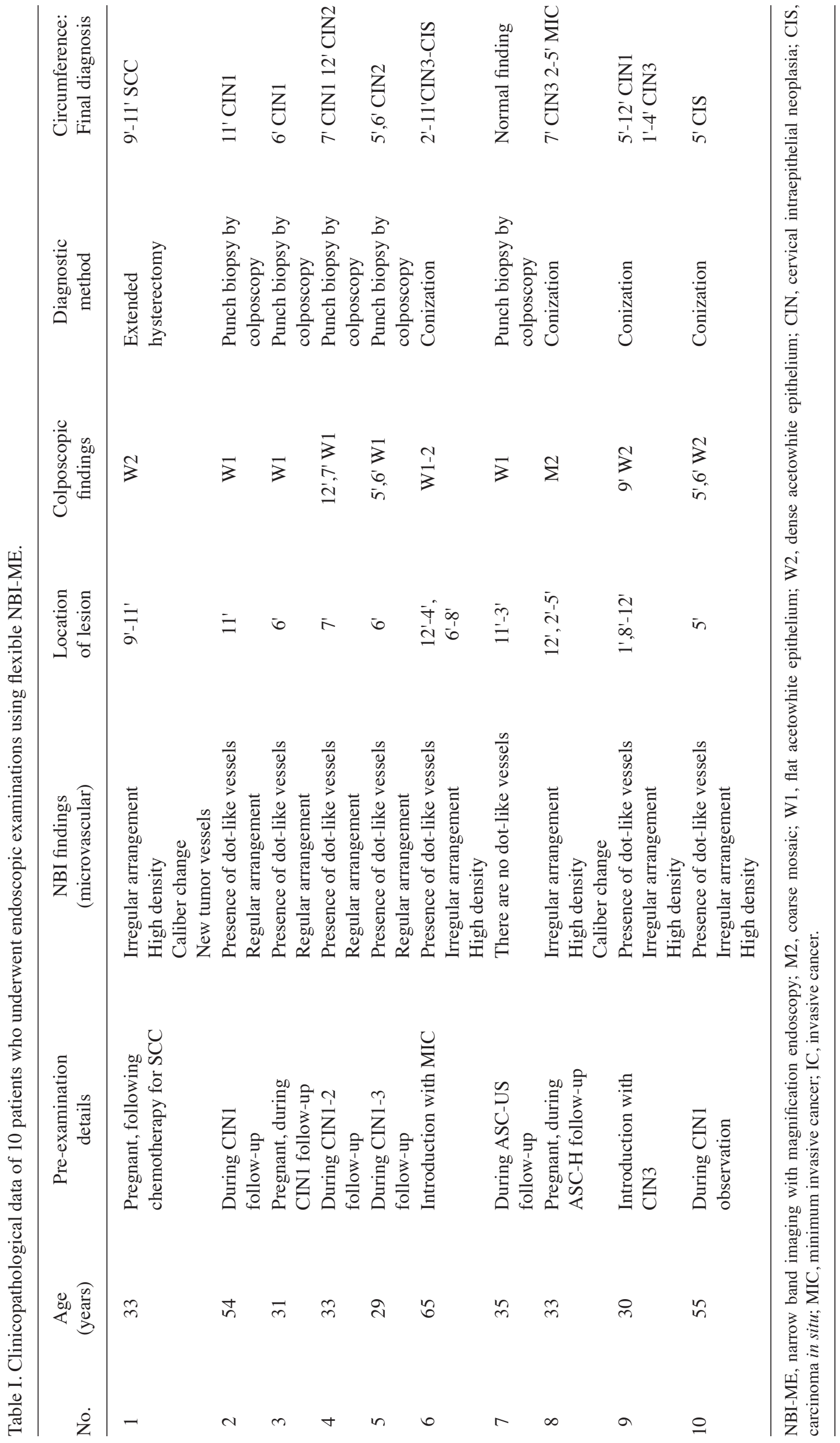


Table II. Microvascular findings via NBI-ME in 10 patients.

\begin{tabular}{|c|c|c|c|c|c|c|c|c|c|c|}
\hline Parameters & Normal & \multicolumn{2}{|c|}{ CIN1 } & \multicolumn{2}{|c|}{ CIN2 } & CIN3 & \multicolumn{2}{|c|}{ CIS } & MIC & IC \\
\hline Total number of patients & 1 & \multicolumn{2}{|c|}{2} & \multicolumn{2}{|c|}{2} & 1 & \multicolumn{2}{|c|}{2} & 1 & 1 \\
\hline \multicolumn{11}{|c|}{ Characteristics of NBI-ME findings } \\
\hline Presence of dots & 0 & 1 & 1 & 1 & 1 & 1 & 1 & 1 & 0 & 0 \\
\hline Irregular arrangement of dots & 0 & 0 & 0 & 0 & 0 & 1 & 1 & 1 & 1 & 1 \\
\hline High density of dots & 0 & 0 & 0 & 0 & 0 & 1 & 1 & 1 & 1 & 1 \\
\hline Caliber change of vessels & 0 & 0 & 0 & 0 & 0 & 0 & 0 & 0 & 1 & 1 \\
\hline New tumor vessels & 0 & 0 & 0 & 0 & 0 & 0 & 0 & 0 & 0 & 1 \\
\hline
\end{tabular}

NBI-ME, narrow band imaging with magnification endoscopy; dots, dilation of intrapapillary protruded loop vessels; CIN, cervical intraepithelial neoplasia; CIS, carcinoma in situ; MIC, minimum invasive cancer; IC, invasive cancer.
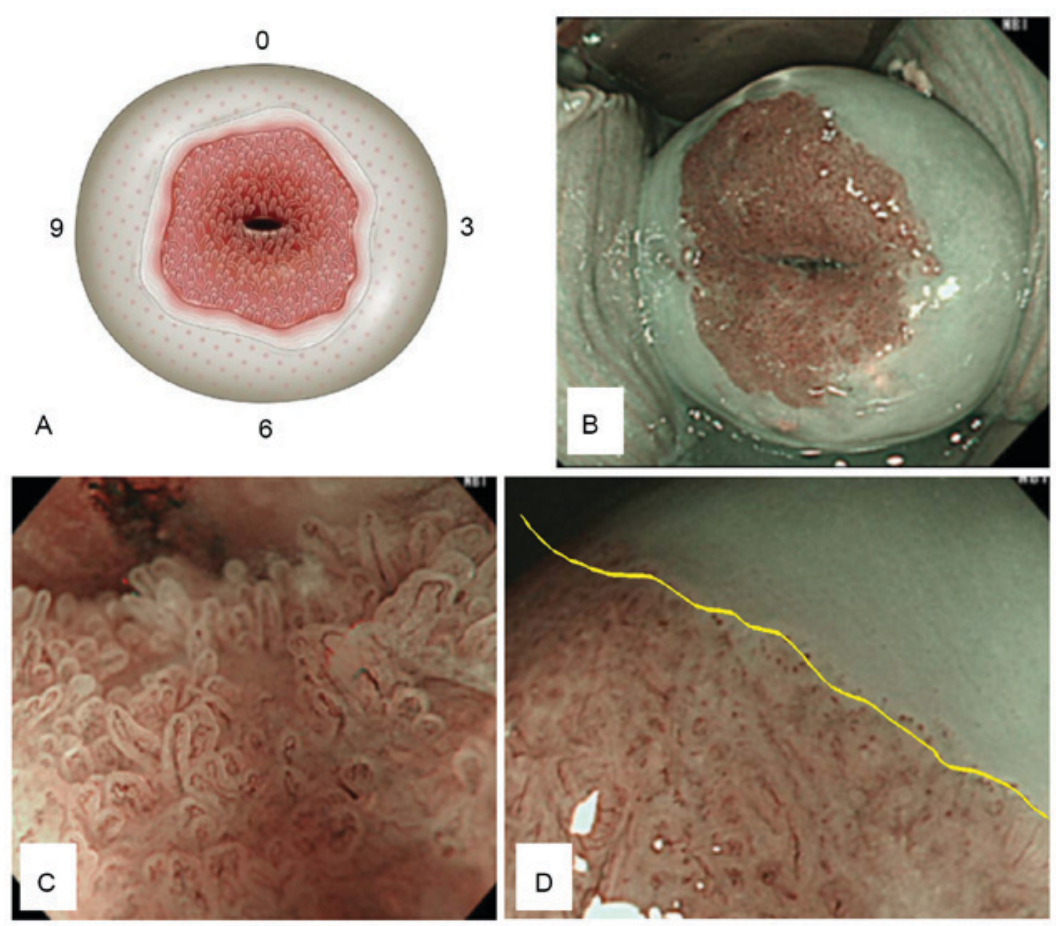

Figure 1. Normal uterine cervix. (A) Schema of a normal uterine cervix; internal ostium of the uterus; columnar, transitional and squamous epithelium (in order from the inside). (B) Distant view of cervix using NBI mode. (C) NBI-ME image of normal columnar epithelium, with villous-like structures. (D) NBI-ME image of normal transitional epithelium (inside the yellow line), with a low height structure and NBI-ME image of normal squamous epithelium (outside the yellow line) with absence of structure. NBI-ME, narrow band imaging with magnification endoscopy.
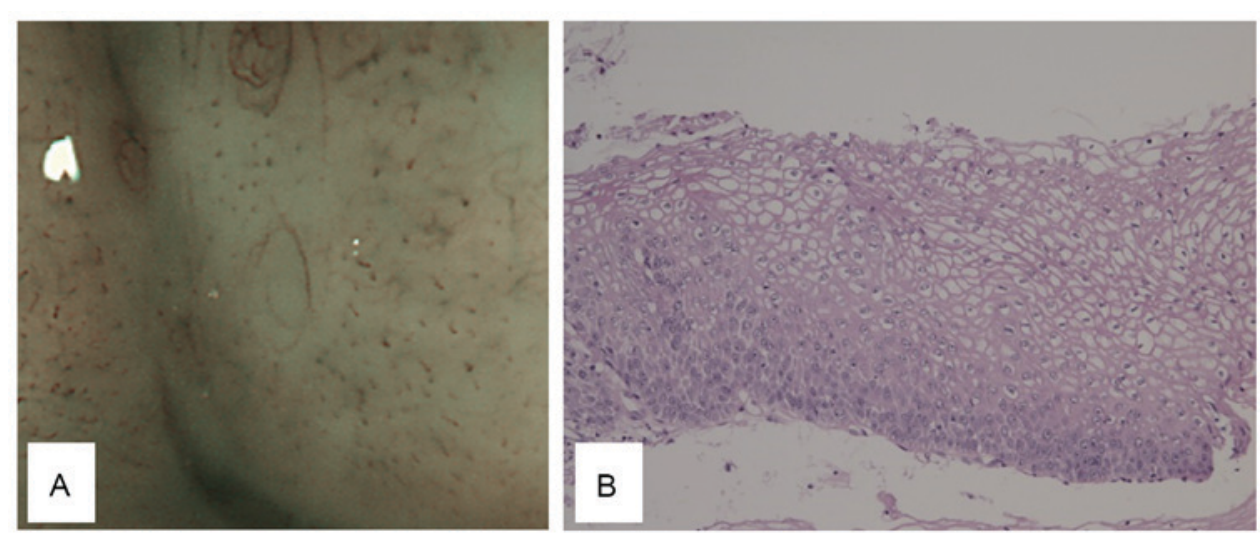

Figure 2. CIN1 morphology. (A) CIN1 tumors present with a slight increase in dots compared with the normal site. (B) The histological findings of CIN1 tumors include the presence of dysplastic squamous cells in the lower third of the epithelium (magnification, x20). CIN, cervical intraepithelial neoplasia. 

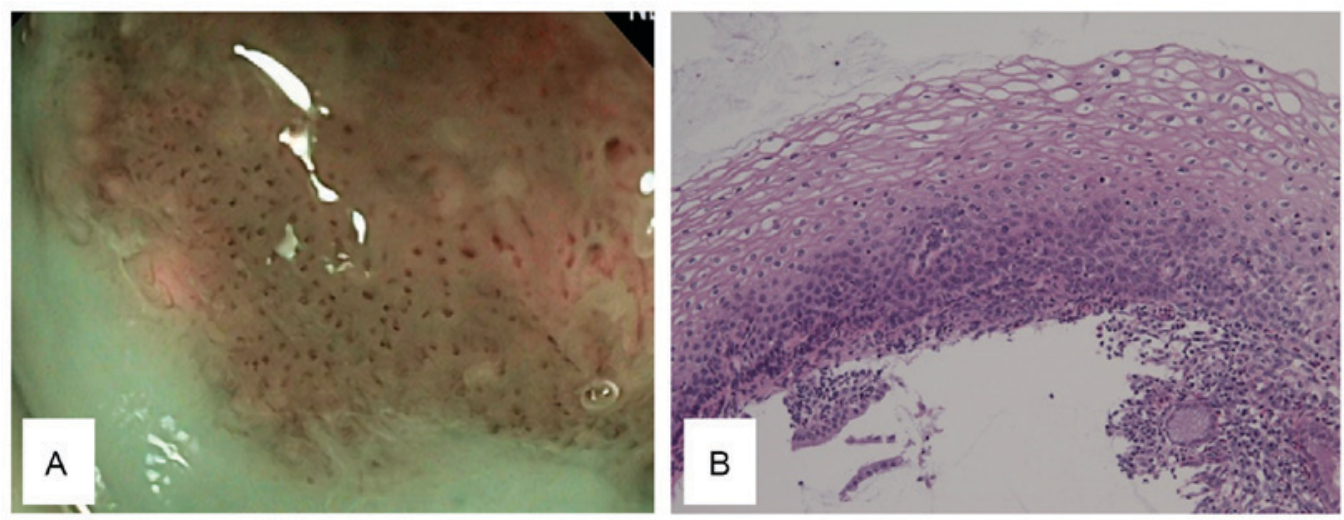

Figure 3. CIN2 morphology. (A) CIN2 tumors present with a mild increase in the number of dots compared with the normal site, with no irregular arrangements. (B) The histological findings of CIN2 tumors include the presence of dysplastic cells in the basal two-thirds of the epithelium, and differentiation and maturation in the upper half of the epithelium (magnification, x20). CIN, cervical intraepithelial neoplasia.
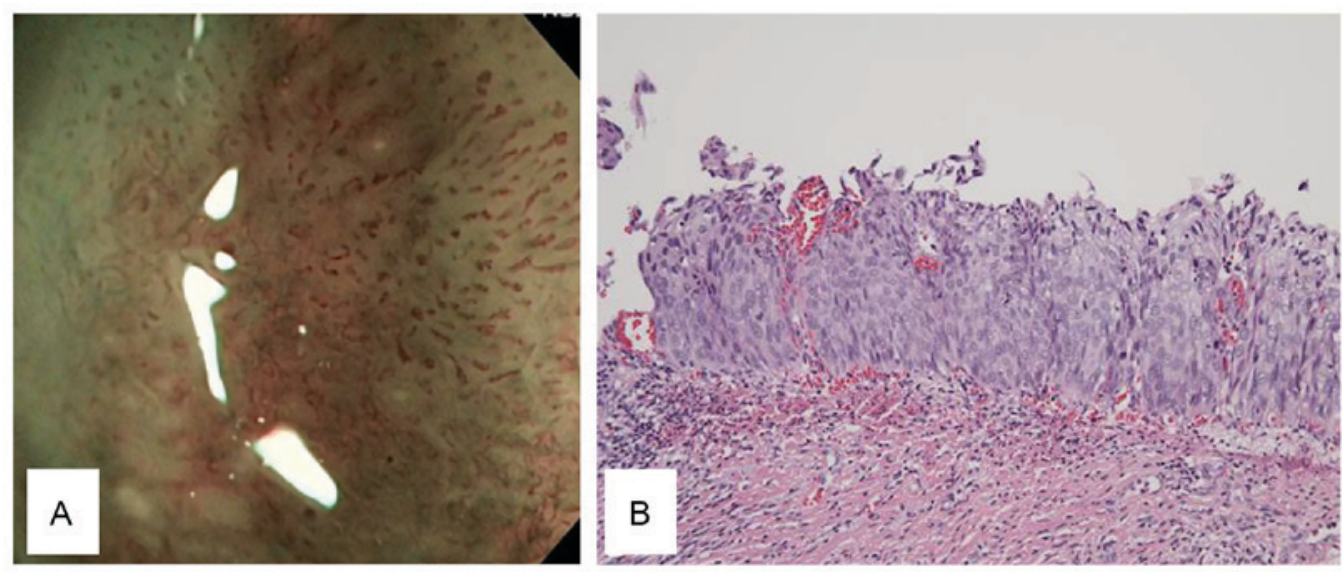

Figure 4. CIN3 morphology. (A) CIN3 tumors present with elongated dots with a slightly irregular arrangement and a large increase in the number of dots compared with the normal site. (B) The histological findings of CIN3 tumors include the presence of dysplastic squamous cells throughout the entire thickness of the epithelium and vascular hyperplasia (magnification, x20). CIN, cervical intraepithelial neoplasia.
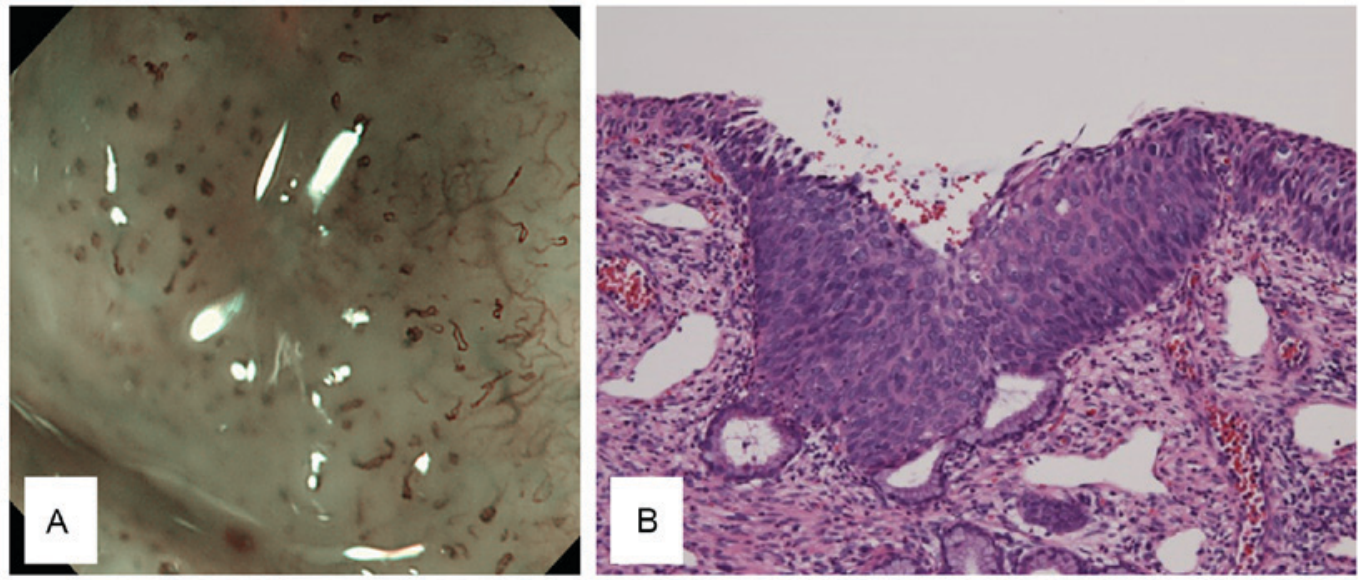

Figure 5. CIS morphology. (A) CIS presents with elongated dots with severely irregular arrangements and a large increase in the number of dots compared with the normal site. (B) The histological findings of CIS include neoplastic cells from the base to the surface with cytological atypia, bristle mitoses and vascular hyperplasia (magnification, x20). CIS, carcinoma in situ.

\section{Discussion}

An NBI system has been proposed to be valuable for the diagnosis of early GI neoplasm (6-12). The NBI system is currently utilized in the gynecological field. It has previously been demonstrated that colposcopy with the NBI system is effective for the diagnosis of cervical adenocarcinoma (14) and that flexible hysteroscopy with NBI may be useful for the 
Table III. Proposed microvascular classification system via NBI-ME for uterine cervical neoplasms.

\begin{tabular}{|c|c|c|c|c|c|c|c|}
\hline Classification & Normal & CIN1 & CIN2 & CIN3 & CIS & MIC & $\mathrm{IC}$ \\
\hline \multicolumn{8}{|l|}{ Values } \\
\hline Vascular change & $\begin{array}{l}\text { No vascular } \\
\text { dilatation }\end{array}$ & $\begin{array}{l}\text { Presence } \\
\text { of dots }\end{array}$ & $\begin{array}{l}\text { Presence } \\
\text { of dots }\end{array}$ & $\begin{array}{l}\text { Elongation } \\
\text { of dots }\end{array}$ & $\begin{array}{l}\text { Elongation } \\
\text { of dots }\end{array}$ & $\begin{array}{l}\text { Multi- } \\
\text { caliber } \\
\text { vessel } \\
\text { changes }\end{array}$ & $\begin{array}{l}\text { New tumor } \\
\text { vessels } \\
\text { ( } 2 x \text { dilated } \\
\text { vessels, like } \\
\text { IPCL) }\end{array}$ \\
\hline Arrangement & Regular & Regular & Regular & $\begin{array}{l}\text { Irregular } \\
\text { (slight) }\end{array}$ & $\begin{array}{l}\text { Irregular } \\
\text { (severe) }\end{array}$ & $\begin{array}{l}\text { Irregular } \\
\text { (severe) }\end{array}$ & $\begin{array}{l}\text { Irregular } \\
\text { (severe) }\end{array}$ \\
\hline $\begin{array}{l}\text { Density } \\
\text { Postscript }\end{array}$ & Regular & Slight & Mild & High & High & $\begin{array}{l}\text { High } \\
\text { Crawling } \\
\text { vessel }\end{array}$ & $\begin{array}{l}\text { High } \\
\text { Willow } \\
\text { branch }\end{array}$ \\
\hline
\end{tabular}

Microvascular features of cervical neoplasms of every stage identified by NBI-ME. NBI-ME, narrow band imaging with magnification endoscopy; dots, dilation of intrapapillary protruded loop vessels; CIN, cervical intraepithelial neoplasia; CIS, carcinoma in situ; MIC, minimum invasive cancer; IC, invasive cancer; IPCL, intra-epithelial papillary capillary loop.
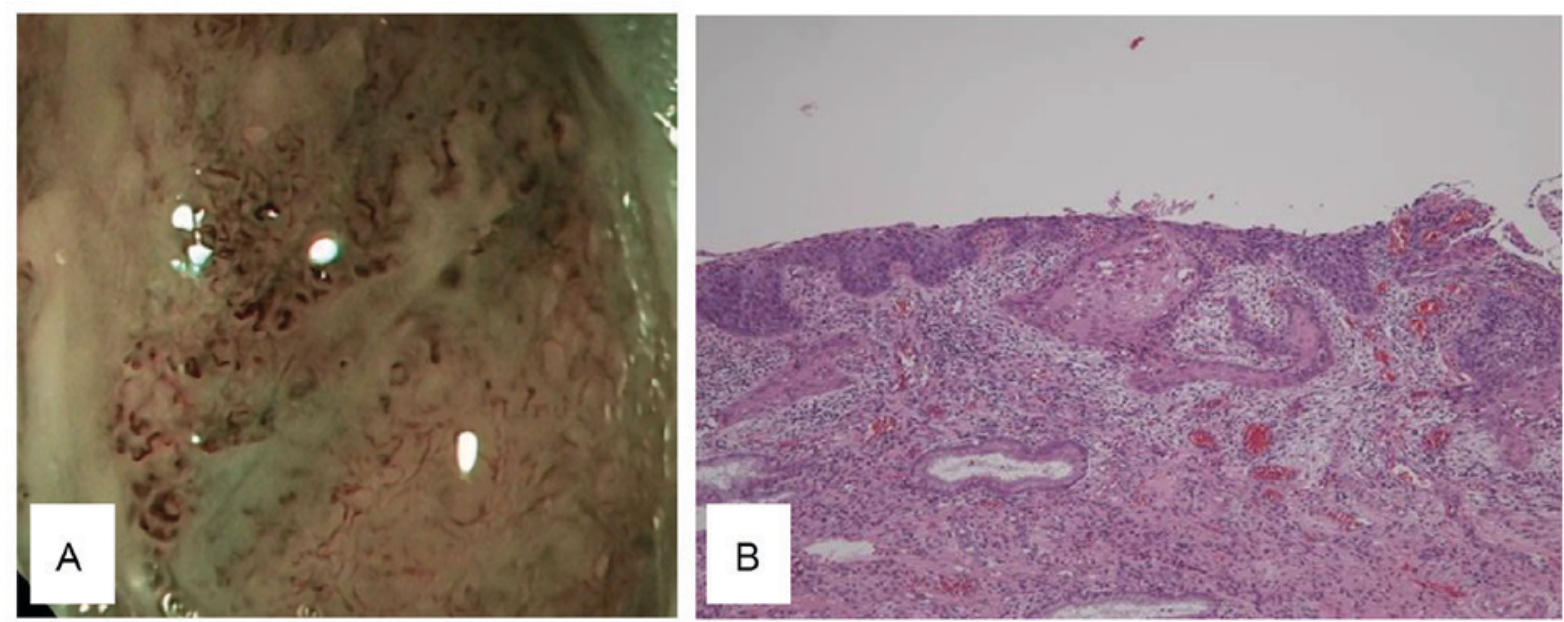

Figure 6. MIC morphology. (A) MIC presents with high density crawling vessels in irregular arrangements and caliber changes. (B) The histological findings of MIC include budding of malignant cells downward into the underlying stroma, with lymphocytic infiltrate and vascular hyperplasia (magnification, $\mathrm{x} 4$ ). MIC, microinvasive cancer.
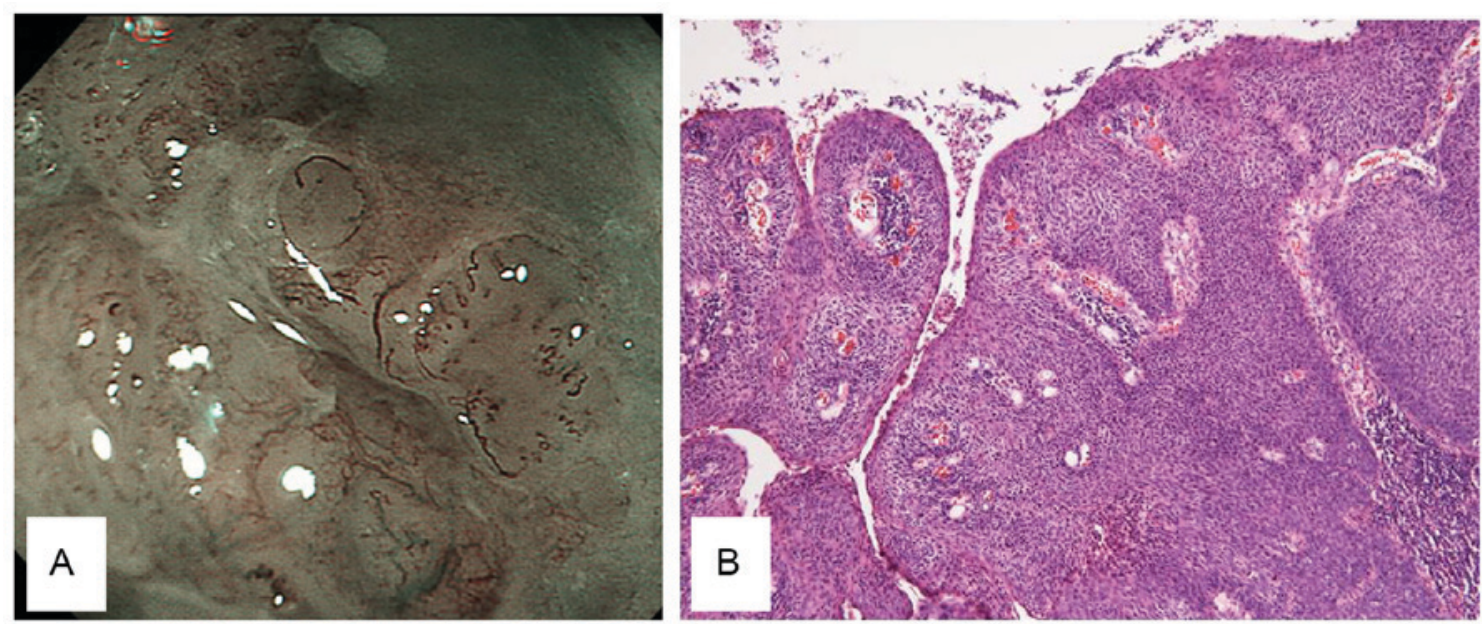

Figure 7. IC morphology. (A) IC presents with willow branch vessels and new tumor vessels with irregular arrangements and high densities. (B) The histological findings of IC include malignant squamous cells with abundant eosinophilic cytoplasms, distinct cell borders and individual cell keratinization and vascular hyperplasia (magnification, x10). IC, invasive cancer. 
diagnosis of malignant endometrial lesions (15). However, it is difficult to evaluate the microvascular pattern of tumors in detail, because the NBI mode does not have a high magnification function. Inoue et al (6) demonstrated that it is possible to classify the micro-vascular pattern of intrapapillary capillary loops in squamous esophageal neoplasms by NBI-ME. Furthermore, Yao et al $(7,8)$ described a micro-vascular and micro-surface classification system for tubular epithelium that is useful for distinguishing early gastric neoplasms from other lesions.

In accordance with these results, NBI-ME was expected to be an excellent tool for the diagnosis of uterine cervical neoplasms, similar to the diagnoses of epithelial neoplasms of the GI tract. In the present study, NBI-ME was demonstrated to reveal different characteristics of tumors of different stages, as listed in Table III. This is the first report of the potential diagnostic value of NBI-ME for uterine cervical tumors.

GI endoscopists currently serve an important role in other areas in addition to gastroenterology. The first-ever application of endoscopic hemostatic forceps for active cervical bleeding was previously reported by our group (16). This idea was based on the advances made in endoscopic skills and devices. Endoscopic submucosal dissection (ESD) for malignant epithelial tumors has been well established in the field of gastroenterology. ESD facilitates technical maneuvers under direct vision. Novel modalities, including NBI-ME, and minimally invasive endoscopic treatments, including ESD, may have multiple benefits compared with conventional procedures. For example, NBI-ME is able to detect early pharyngeal carcinomas (17), and ESD endoscopists are able to perform curative resection of pharyngeal epithelial carcinomas (18). The collaboration of gastro-endoscopists and physicians in other fields is now an option for overcoming conventional issues. Laparoscopic and endoscopic cooperative surgery has been introduced clinically for local resection of intraluminal type GI stromal tumors (19). Endoscopists are able to perform endoscopic full-thickness resection (20) with an accurately set marginal line and controlled bleeding. As one method of natural orifice transluminal endoscopic surgery, gastro-endoscopists, surgeons, and gynecologists act cooperatively when performing cholecystectomy via the vagina (21).

Therefore, the introduction of NBI-ME for uterine cervical lesions in patients treated collaboratively by GI endoscopists and gynecologists is reasonable and represents a novel, team approach. NBI-ME has certain advantages over colposcopy. First, endoscopy (x80 magnification) has a higher magnification power than colposcopy (x23.7 magnification). Second, it is possible to accurately acquire the target lesion with biopsy forceps, and spray acetic acid under direct vision through the scope. Third, it is possible to observe the cervix by endoscopy in a left lateral decubitus position instead of the lithotomy position. However, the present study was a single-center, preliminary study with a small sample size. In addition, the limitation of the present study is that, in our experience, only squamous cell lesions are involved except for columnar lesions. A large prospective study is required to confirm the diagnostic value of this novel method. A comparative prospective study with a large number of cases is now being performed at Kagawa University Hospital.
In conclusion, the present study demonstrated that NBI-ME may be a valuable option for the diagnosis of uterine cervical epithelial tumors, may result in the establishment of a novel classification system, and may contribute to further developments in the gynecologic field.

\section{References}

1. Arbyn M, Autier P and Ferlay J: Burden of cervical cancer in the 27 member states of the European Union: Estimates for 2004 Ann Oncol 18: 1423-1425, 2007.

2. Boutas I, Sofoudis C, Kalampokas E, Anastasopoulos C, Kalampokas T and Salakos N: Fertility preservation in women with early stage cervical cancer. Review of the literature. Eur J Gyneacol Oncol 35: 373-377, 2014.

3. Coronado PJ and Fasero M: Correlating the accuracy of colposcopy with practitioner experience when diagnosing cervical pathology using the dynamic spectral imaging system. Gynecol Obstet Invest 78: 224-229, 2014.

4. Wentzensen N, Walker JL, Gold MA, Smith KM, Zuna RE, Mathews C, Dunn ST, Zhang R, Moxley K, Bishop E, et al: Multiple biopsies and detection of cervical cancer precursors as colposcopy. J Clin Oncol 33: 83-89, 2015.

5. Duggan MA and Nation J: An audit of the cervical cancer screening histories of 246 women with carcinoma. J Low Genit Tract Dis 16: 263-270, 2012.

6. Inoue H, Kaga M, Ikeda H, Sato C, Sato H, Minami H, Santi EG, Hayee B and Eleftheriadis N: Magnification endoscopy in esophageal squamous cell carcinoma: A review of the intrapapillary capillary loop classification. Ann Gastroenterol 28: 41-48, 2015.

7. Yao K: How is the VS (vessel plus surface) classification system applicable to magnifying narrow-band imaging examinations of gastric neoplasias initially diagnosed as low-grade adenomas? Gastric Cancer 15: 118-120, 2012.

8. Yao K, Oishi T, Matsui T, Yao T and Iwashita A: Novel magnified endoscopic findings of microvascular architecture in intramucosal gastric cancer. Gastrointest Endosc 56: 279-284, 2002.

9. Goda K, Dobashi A and Tajiri H: Perspectives on narrow-band imaging endoscopy for superficial squamous neoplasms of the orohypopharynx and esophagus. Dig Endosc 26 (Suppl 1): 1-11, 2014.

10. Yamada S, Doyama H, Yao K, Uedo N, Ezoe Y, Oda I, Kaneko K, Kawahara Y, Yokoi C, Sugiura Y, et al: An efficient diagnostic strategy for small, depressed early gastric cancer with magnifying narrow-band imaging: A post-hoc analysis of a prospective randomized controlled trial. Gastrointest Endosc 79: 55-63, 2014.

11. Ezoe Y, Muto M, Uedo N, Doyama H, Yao K, Oda I, Kaneko K, Kawahara Y, Yokoi C, Sugiura Y, et al: Magnifying narrowband imaging is more accurate than conventional white-light imaging in diagnosis of gastric mucosal cancer. Gastoroentelrology 141: 2017-2025.e3, 2011.

12. Tanaka S and Sano Y: Aim to unify the narrow band imaging (NBI) magnifying classification for colorectal tumors: Current status in Japan from a summary of the consensus symposium in the 79th annual meeting of the Japan gastroenterological endoscopy society. Dig Endosc 23 (Suppl 1): 131-139, 2011.

13. Gono K, Obi T, Yamaguchi M, Ohyama N, Machida H, Sano Y, Yoshida S, Hamamoto Y and Endo T: Appearance of enhanced tissue features in narrow-band endoscopic imaging. J Biomed Opt 9: 568-577, 2004.

14. Fujii T, Nakamura M, Kameyama K, Saito M, Nishio H, Ohno A, Hirao N, Iwata T, Tsukazaki K and Aoki D: Digital colposcopy for the diagnosis of cervical adenocarcinoma using a narrow band imaging system. Int J Gynecol Cancer 20: 605-610, 2010.

15. Kisu J, Banno K, Kobayashi Y, Ono A, Masuda K, Ueki A, Nomura H, Hirasawa A, Abe T, Kouyama K, et al: Flexible hysteroscopy with narrow band imaging (NBI) for endoscopic diagnosis of malignant endometrial lesions. Int J Oncol 38: 613-618, 2011

16. Kobara H, Mori H, Rafiq K, Fujihara S, Nishiyama N, Morishita A, Goda Y, Kanenishi K, Hata T and Masaki T: Application of endoscopic hemostatic forceps for uterine cervical bleeding. Gastrointest Endosc 81: 234-235, 2015.

17. Nakanishi H, Doyama H, Takemura K, Yoshida N, Tsuji K, Takeda Y, Asahina Y, Kito Y, Ito R, Hayashi T, et al: Detection of pharyngeal cancer in the overall population undergoing upper GI endoscopy by using narrow-band imaging: A single-center experience, 2009-2012. Gastrointest Endosc 79: 558-564, 2014. 
18. Okada K, Tsuchida T, Ishiyama A, Taniguchi T, Suzuki S, Horiuchi Y, Matsuo Y, Yoshizawa N, Suganuma T, Omae M, et al: Endoscopic mucosal resection and endoscopic submucosal dissection for en bloc resection of superficial pharyngeal carcinomas. Endoscopy 44: 556-564, 2012.

19. Hiki N, Nunobe S, Matsuda T, Hirasawa T, Yamamoto Y and Yamaguchi T: Laparoscopic endoscopic cooperative surgery. Dig Endosc 27: 197-204, 2015.
20. Mori H, Kobara H, Fujihara S, Nishiyama N, Ayagi M, Matsunaga T, Yachida T and Masaki T: Establishment of the hybrid endoscopic full-thickness resection of gastric gastrointestinal stromal tumors. Mol Clin Oncol 3: 18-22, 2015.

21. Federlein M, Borchert D, Müller V, Atas Y, Fritze F, Burghardt J, Elling D and Gellert K: Transvaginal video-assisted cholecystectomy in clinical practice. Surg Endosc 24: 2444-2452, 2010. 